Canadian

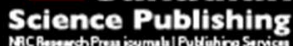

Applied Physiology, Nutrition, and Metabolism Physiologie appliquée, nutrition et métabolisme

\title{
Genetic Characterization of Physical Activity Behaviours in University Students Enrolled in Kinesiology Degree Programs
}

\begin{tabular}{|r|l|}
\hline Journal: & Applied Physiology, Nutrition, and Metabolism \\
\hline Manuscript ID & apnm-2016-0441.R3 \\
\hline Manuscript Type: & Article \\
\hline Date Submitted by the Author: & 01-Nov-2016 \\
\hline Complete List of Authors: & $\begin{array}{l}\text { Many, Gina; Children's National Medical Center, Research Center for } \\
\text { Genetic Medicine } \\
\text { Kendrick, Zachary; Children's National Health System } \\
\text { Deschamps, Chelsea; University of Calgary, } \\
\text { Sprouse, Courtney; Children's National Health System } \\
\text { Tosi, Laura; Children's National Health System } \\
\text { Devaney, Joseph; Children's National Health System } \\
\text { Gordish-Dressman, Heather; Children's National Health System } \\
\text { Barfield, Whitney; Children's National Health System } \\
\text { Hoffman, Eric; Children's National Health System } \\
\text { Houmard, Joseph; East Carolina University, } \\
\text { Pescatello, Linda; University of Connecticut } \\
\text { Vogel, Hans; University of Calgary } \\
\text { Shearer, Jane; University of Calgary, } \\
\text { Hittel, Dustin; University of Calgary, Medicine }\end{array}$ \\
\hline Keyword: & \begin{tabular}{l} 
Inactivity, Intensity, Behaviour, Genetics, kinesiology < biomechanics \\
\hline
\end{tabular} \\
\hline
\end{tabular}




\section{Genetic Characterization of Physical Activity Behaviours in University Students Enrolled in Kinesiology Degree Programs}

\section{Gina M. Many ${ }^{1,6}$, Zachary Kendrick ${ }^{1}$}

Chelsea L. Deschamps ${ }^{2}$, Courtney Sprouse ${ }^{1}$, Laura L. Tosi ${ }^{1}$, Joseph M. Devaney ${ }^{1}$, Heather Gordish-Dressman ${ }^{1}$, Whitney Barfield ${ }^{1}$, Eric P. Hoffman ${ }^{1}$, Joseph A. Houmard ${ }^{3}$, Linda S. Pescatello ${ }^{4}$ Hans J. Vogel ${ }^{5}$, Jane Shearer ${ }^{2,5}$, Dustin S. Hittel ${ }^{5}$

${ }^{1}$ Genetic Medicine, Children's National Medical Center, Washington DC, USA

${ }^{2}$ Faculty of Kinesiology, University of Calgary, Calgary, Alberta, Canada

${ }^{3}$ Department of Kinesiology, East Carolina University, Greenville, North Carolina, USA

${ }^{4}$ Department of Kinesiology, University of Connecticut; Storrs, Connecticut, USA

${ }^{5}$ Cumming School of Medicine, University of Calgary, Calgary, Alberta, Canada

${ }^{6}$ Departments of Cell, Developmental, and Integrative Biology, University of Alabama at Birmingham (UAB), Birmingham, Alabama, USA

\section{Corresponding Author}

Dr. Dustin S. Hittel, Department of Biochemistry and Molecular Biology, Cumming School of Medicine, University of Calgary, 2500 University Dr. Calgary, Alberta, Canada, T2N1N4

Tel: +1-403-585-6503

Fax: +1-403-284-3553

E-mail: dhhittel@ucalgary.ca 


\begin{abstract}
Studies of physical activity behaviours have increasingly shown the importance of heritable factors such as genetic variation. Non-synonymous polymorphisms of alphaactinin $3(A C T N 3)$ and the $\beta$-adrenergic receptors 1 and $3(A D R B)$ have been previously associated with exercise capacity and cardiometabolic health. We thus hypothesized that these polymorphisms are also related to physical activity behaviors in young adults. To test this hypothesis we examined relationships between ACTN3 (R577X), ARDB1 (Arg389Gly) and ADRB3 (Trp64Arg), and physical activity behaviors in university students. We stratified for student enrollment in kinesiology degree programs compared to non-majors as we previously found this to be a predictor of physical activity. We did not identify novel associations between physical activity and ACTN3. However, the minor alleles of $A D R B 1$ and $A D R B 3$ were significantly underrepresented in kinesiology students compared to non-majors. Furthermore, carriers of the $A D R B 1$ minor allele reported reduced participation in moderate physical activity and increased afternoon fatigue compared to ancestral allele homozygotes. Together, these findings suggest that the heritability of physical activity behaviours in young adults may be linked to nonsynonymous polymorphisms within $\beta$-adrenergic receptors.
\end{abstract}

Key Words: Inactivity, Intensity, Behaviour, Genetics, Kinesiology 


\section{Introduction}

Inactivity and sedentary behaviors contribute to $\sim 5.3$ million deaths annually (Katzmarzyk and Janssen 2004; Lee et al. 2015; Ogden et al. 2014; Rao et al. 2015). A significant proportion of these deaths are due to complications from type 2 diabetes (T2D) and the insulin resistance syndrome that precedes it (Cowie et al. 2006). Regular physical activity is the most effective intervention for the prevention of insulin resistance and T2D (Fiuza-Luces et al. 2013). However, significant variability exists in both the effectiveness of and adherence to prescribed physical activity for health and fitness (de Geus et al. 2014; Houmard et al. 2004; Johnson et al. 2004). Since some of this variability can be attributed to polymorphisms within exercise-related genes, a precision medicine approach is warranted to manage the burden of inactivity-related disease (Bouchard et al. 2011; Bray et al. 2016; de Geus et al. 2014; Lee et al. 2015).

Previous research from our laboratory has identified significant effects of genetics (Deschamps et al. 2015), educational setting and social/geographical factors (Many et al. 2016) on parameters of cardiometabolic fitness (Myslicki et al. 2014) and physical activity behaviors in healthy young university students. For instance, we have recently shown that the common $577 \mathrm{X}$ stop-codon mutation within the gene encoding sarcomeric alpha-actinin $3(A C T N 3)$ is associated with lower cardiovascular fitness (peak $\mathrm{VO}_{2}$ ), increased body fat and an atherogenic metabolite profile relative to carriers of the R577 ancestral allele (Deschamps et al. 2015). These findings support a large body of published research linking the $A C T N 3$ "sports gene" to exercise capacity in both elite and amateur athletes (Chan et al. 2008; Clarkson et al. 2005; Delmonico et al. 2007; Eynon et al. 2014; MacArthur and North 2004; Mills et al. 2001; Norman et al. 2014). In this same 
cohort we determined that students enrolled in accredited kinesiology degree programs in Canada and the United States display improved parameters of insulin sensitivity and increased physical activity levels relative to non-kinesiology majors (Many et al. 2016). Given the significant heritability of physical activity behaviors in young adults $(\sim 84 \%)$, our kinesiology cohort represents a novel population of convenience for investigating the relationship between genetics and physical activity (de Geus et al. 2014; Nedovic et al. 2016).

The $\beta$-adrenergic receptors encoded by the $A D R B$ genes, are catecholaminesensitive, G-coupled transmembrane proteins that are expressed in variety of tissues, including heart, skeletal and smooth muscle, adipose and the brain (Burguete-Garcia et al. 2014; Clement et al. 1995; Numajiri et al. 2012; Snyder et al. 2006; Wagoner et al. 2002; Walston et al. 1995; Widen et al. 1995). Like ACTN3 (Deschamps and Hittel 2016), non-synonymous (amino acid changing) variants of the $\beta$-adrenergic receptors genes $A R D B 1$ (Arg389Gly) and ADRB3 (Trp64Arg) have been associated with both insulin resistance and athletic performance (Burguete-Garcia et al. 2014; Clement et al. 1995; Walston et al. 1995; Widen et al. 1995). Although the mechanisms are not well established as $A C T N 3, A D R B$ receptors in the brain have been shown to modulate anxiolytic (anxiety reducing) behaviours (Stemmelin et al. 2008) and thus may influence the perception of exercise as a means to reduce anxiety (Pedersen and Saltin 2015).

To test this hypothesis we examined $A C T N 3, A D R B 1$ and $A D R B 3$ gene variants in relation to physical activity behaviors in a population of healthy young university students. Findings from this study may be of importance for identifying genetic markers 
associated with physical activity that can be used for targeting physical activity interventions in at risk individuals.

\section{Methods and Materials}

\section{Participants}

All participants were a part of the Assessing Inherited Markers of Metabolic Syndrome in the Young (AIMMY) study described previously (Deschamps et al. 2015; Karlos et al. 2013; Klein et al. 2014; Many et al. 2016). University students were enrolled at three recruiting sites: (UC) University of Calgary (n=197, Calgary, Canada), (ECU) East Carolina University ( $\mathrm{n}=91$, Greenville, NC) and (UM) University of Massachusetts ( $n=207$, Amherst, MA). This study was approved by the Conjoint Health Research Ethics Board at the University of Calgary (Ethics ID: E23521) and is registered under the clinicaltrials.gov identifier NCT00966407. Written informed consent for genetic and all other testing was obtained from all subjects before participation and was conducted under the provisions of the Declaration of Helsinki. Subjects were: (1) between the ages of 18 and 35 years; (2) had completed puberty; and (3) willing and able to provide informed consent. At all sites, recruitment occurred on-campus using posters, information on campus-wide monitors, brief classroom sessions and the university's website. All eligible, consenting participants were considered to be healthy at the time of enrolment. Health was defined as an absence of: (1) evidence of clinically relevant systemic disease associated with metabolic disorders ; (2) chronic use of glucocorticoid or appetite suppressants; (3) the use of drugs that alter glucose metabolism or other medications known to alter blood levels being tested in this study; (4) previous diagnosis or treatment 
for any hematologic-oncologic disorder; (5) history or current treatment for an eating disorder; (6) current treatment for weight loss; (7) history of bariatric surgery; (8) history of neurosurgical procedure.

\section{Clinical Blood Measures}

Blood samples were collected in de-identified tubes after an 8-12 hour, overnight fast. Blood for lipoprotein assays (LDL-C, High-Density Lipoprotein Cholesterol (HDLC), Total Cholesterol (TC), and Triglycerides (TG)) as well as insulin, glucose and HbA1c was collected using serum stopper tubes containing a clot activator and a silicon gel separator. After collection, samples were spun at $3000 \mathrm{rpm}$ for 10 minute and stored at $2-8^{\circ} \mathrm{C}$ until being transported to Calgary Lab Services (Calgary, AB) or Quest Diagnostics (Madison, NJ) for analysis as described previously (Deschamps et al. 2015; Karlos et al. 2013; Many et al. 2016).

\section{Genotyping}

Genomic DNA for genetic analysis was isolated from peripheral blood as described previously. Blood samples were collected in tubes containing an ethylene diamine tetra-ascetic acid (EDTA) anticoagulant and were stored at $2-8^{\circ} \mathrm{C}$ for a maximum of one week before being sent to the Children's National Medical Centre (CNMC) in Washington, DC without subject identification. The ACTN3 R577X (rs1815739), ADRB1 Arg389Gly (rs1801253) and ADRB3 Trp64Arg single nucleotide polymorphisms (SNPs) (rs4994) were identified using TaqMan allele discrimination assay (Deschamps et al. 2015). 


\section{Fitness Assessment}

Seated resting blood pressure and heart rate measures were taken 3 times over 2 separate visits using an automated monitor cuff. Grip strength was assessed using an Almedic 100kg hand grip dynamometer (Almedic, Montreal, QC, Canada). Body mass index (BMI) was calculated by dividing the subjects height in meters by their weight in $\mathrm{kg}^{2}$. Percent body fat $(\% \mathrm{BF})$ and bone mineral density (BMD) was measured using a dual-energy x-ray absorptiometry scan (DXA) (Hologic QDR 4500A scanner, Hologic Inc, Walthan, MA.). $\mathrm{VO}_{2}$ peak was assessed using the Bruce treadmill protocol as an indicator of cardiovascular fitness. Oxygen consumption was assessed with a Hans Rudolph nonbreathing 2-way valve mouthpiece and a ParvoMedics TrueOne 2400 metabolic cart (ParvoMedics, Sandy, UT) (Shah 2013).

\section{Questionnaires}

Family history, ethnicity, diet and physical activity levels were recorded by selfreport using secure online questionnaires and an iPad as described previously (Many et al. 2016). Self-reported physical activity was assessed via a 12-month Paffenbarger physical activity survey from which, weekly energy expenditure was calculated from the time and energy (metabolic equivalents [METs]) spent participating in leisure and nonleisure physical activities (Simpson et al. 2015). Further, subjects were asked to divide the time spent engaging in light, moderate, and vigorous-intensity physical activity as well as sitting and exercise intensity over a typical 24-hour weekday and weekend (Many et al. 2016). To assess exercise intensity specifically we used the Borg Category Ratio 010 (Borg CR-10) rate of perceived exertion (RPE) scale where 0 means "rest" and 10 means "maximal exertion" (Irving et al. 2006). The Epworth Sleepiness Scale (ESS) was 
used to assess daytime sleepiness (Johns 1991). Finally, students at the University of Calgary and East Carolina University recruitment sites $(n=288)$ were asked to report their college major (kinesiology vs non-kinesiology major) as described previously (Many et al. 2016).

\section{Statistical Analysis}

Unless otherwise stated, all statistical analyses were performed using SPSS Statistics, version 20 (IBM). All data are presented as mean \pm SEM. To test for homogeneity of $A C T N 3, A D R B 1$ and $A D R B 3$ genotype frequencies between kinesiology students and non-majors $\chi^{2}$ values were estimated using genotype numbers as described previously (MacArthur and North 2004).

We used a dominant genetic model for all genotype associations. Age and sex were used as covariates except for when sexes were being compared. Analysis of covariance (ANCOVA) with the Sidak method for post-hoc multiple comparisons adjustment was used for post-hoc multiple comparisons adjustment of $P$ values (Lee et al. 2015). All resulting adjusted means are shown as transformed values as those are the numbers used for statistical models.

\section{Results}

\section{AIMMY Subject Characteristics}

Of the 288 participants enrolled in AIMMY from the UC and ECU sites, 150 $(52 \%)$ subjects were female and $138(48 \%)$ were male with a mean age of $22.4 \pm 2.8$ (age range 18-35, Table 1). Among AIMMY participants, 223 (77.4\%) self-identified as Caucasian, $27(9.4 \%)$ as Asian, $19(6.6 \%)$ as African American, 11 (3.8\%) as Other or 
not-specified and $8(2.8 \%)$ as Hispanic or Latino. Kinesiology (KNES) majors exhibited significantly lower total body fat, lower fasting insulin levels, HOMA-IR and a higher $\mathrm{VO}_{2}$ peak (Table 1) compared to non-majors (NON). KNES majors also reported significantly higher physical activity levels compared to NON-majors and self-reported "regular" exercise to be at a higher intensity as captured by the Borg CR-10 scale (Table 2). Additional physical activity and dietary data from this cohort have been published previously (Deschamps et al. 2015; Many et al. 2016).

For population verification and further genetic analyses, an additional 207 University of Massachusetts students without faculty information (KNES vs NON) were added to the original AIMMY cohort creating a combined cohort of 495 individuals, 229 (46.3\%) Female, 266 (53.7\%) Male).

\section{Genetic Analysis}

As a means of ensuring genotyping accuracy we determined that the ACTN3 rs1815739 Minor Allele Frequency (MAF) was in Hardy-Weinberg Equilibrium (HWE) in both KNES majors $(\mathrm{MAF}=37, \mathrm{p}=0.99)$ and NON-majors $(\mathrm{MAF}=45, \mathrm{p}=0.60)$ in our combined cohort. Further, there were no significant differences in the distribution of ACTN3 genotypes $(P=0.423)$ (Figure 1), nor were there any additional associations with cardiometabolic or fitness traits other than those reported previously by our lab (Peak $\mathrm{VO}_{2}$, Systolic \& Diastolic Blood Pressure and \% Body Fat) (Deschamps et al. 2015).

Similarly, we determined that $A D R B 1 \mathrm{rs} 1801253(\mathrm{MAF}=32 \%, \mathrm{p}=0.17)$ and ADRB3 rs4994 $(\mathrm{MAF}=7.4 \%, \mathrm{p}=0.31)$ loci were also in HWE in the combined AIMMY cohort. However a Pearson's $\chi^{2}$ test identified significant differences in the distribution of $A D R B 1 \mathrm{CC}, \mathrm{CG}$ and $\mathrm{GG}$ genotypes $(P=0.004)$ and $A D R B 3 \mathrm{AA}, \mathrm{AG}$ and GG genotypes 
$(P=0.018)$ between kinesiology students and non-major sub-populations (Figure 1$)$. In the case of $A D R B 1,32 \%$ (32) kinesiology students carried one or more copies of the minor G/Arg389Gly allele compared to 52\% (98) non-majors. For ADRB3, 7\% (7) of kinesiology students carried one or more copies of the minor G/Trp64Arg allele compared to $14 \%$ (26) non-majors. Taken together these findings inspired a deeper investigation of the relationship between $A D R B$ genotypes, cardiometabolic and fitness characteristics of our AIMMY cohort (Tables 1 and 2) that may underlie differences in the population structure of kinesiology students (Many et al. 2016). The observed MAFs were within the range of population genetics data from the 1000 genomes (Kuehn 2012) and NIH Exome Sequencing Project cohorts (Auer et al. 2012) for ACTN3 (37.2\%) $A R D B 1(30.0 \%)$ and $A R D B 3(11.5 \%)$.

In the original $(n=288$, Table $3 A)$, verification $(n=207$, Table $3 B)$ and combined (n=495, Table 3C) AIMMY cohorts, ADRB 1 CG/GG individuals reported significantly fewer calories expended during moderate-type physical activity. Whereas $A D R B 1$ $\mathrm{CG} / \mathrm{GG}$ genotypes in the original cohort reported increased "afternoon fatigue" $(P=0.04)$ compared to $\mathrm{CC}$ homozygotes (Table 3A) these differences persisted below the threshold for statistical significance in the verification $(p=0.06$, Table $3 B)$ and combined $(p=0.057$, Table 3C) AIMMY cohorts. ADRB 1 CG/GG individuals also exhibited significantly lower peak $\mathrm{VO}_{2}$ in our combined AIMMY cohort (Table 3C) that was not apparent in the smaller cohorts. Taken together, these findings indicate a role for $A R D B 1$ genotype in voluntary exercise that supports previous associations with exercise capacity (Wagoner et al. 2002). Because the mean values for both $A D R B 1$ heterozygotes (CG) and 
homozygotes $(\mathrm{GG})$ were similar and because of the relatively low numbers of risk allele homozygotes we used a dominant genetic model to calculate associations.

In our original cohort, individuals with $A D R B 3 \mathrm{AG} / \mathrm{GG}$ genotypes scored significantly lower on the Borg CR10 RPE scale when asked to assess their "normal" intensity level during exercise (Table 3A). Although these differences were not significant in the verification cohort $(p=0.07$, Table $3 B)$ they were apparent in female subjects in the combined larger cohort $(\mathrm{p}=0.05, \mathrm{n}=229)$. We also identified significant associations between $A D R B 3$ genotype, fasting triglyceride levels and HOMA-IR in female subjects only wherein possession of 1 or more copy of the $\mathrm{G}$ allele was associated with higher triglycerides and HOMA-IR (Table 3C). These findings are consistent with the role of beta-adrenergic receptors in the regulation of lipolysis and thermogenesis in white and brown adipose tissue(Chang et al. 2012; Ueta et al. 2012). These findings also support previous research linking the ADRB3 Trp64Arg polymorphism with increased susceptibility to insulin resistance and type 2 diabetes (Sakane et al. 2016) (Fujisawa et al. 1996).

Finally, the associations of $A D R B 3$ genotypes with the perception of exercise intensity and $A D R B 1$ with afternoon fatigue were only significant in NON-majors $(n=198)$ (data not shown). Although these associations may be due to reduced statistical power in the smaller KNES cohort ( $\mathrm{n}=99)$, they may also indicate that educational setting/environment can override genotype-associated physical activity behaviors.

\section{Discussion}

We have discovered that common polymorphisms of the $\beta$-adrenergic receptors 1 and 3 are significantly underrepresented in a population of healthy young university 
students enrolled in kinesiology degree programs. Carriers of the ADRB $1 \mathrm{G}$ allele expended on average, 776 fewer kilocalories per week participating in moderate-intensity physical activities, experienced greater afternoon fatigue and exhibited lower cardiovascular fitness (peak $\mathrm{VO}_{2}$ ) compared to homozygous carriers of the ancestral $\mathrm{C}$ allele. Similarly, individuals with one or more copy of the $A D R B 3 \mathrm{G}$ allele reported lower exertion levels during regular exercise, higher fasting triglycerides and higher HOMA-IR values (in females) indicating lower sensitivity to insulin. Three of these characteristics (Moderate Sports, HOMA-IR and Peak $\mathrm{VO}_{2}$ ) were also different in comparing kinesiology with non-major cohorts (Tables 1 and 2) suggesting that $\beta$-adrenergic receptor genetics play a role in determining the population structure of our kinesiology cohort. By way of contrast, ACTN3 R577X alleles were equally distributed between kinesiology students and non-majors despite the many associations of this wellcharacterized "exercise performance" gene with cardiometabolic and muscle strength characteristics (Deschamps et al. 2015). Taken together, these convergent lines of experimental evidence indicate that $A R D B 1$ and $A D R B 3$ polymorphisms influence voluntary participation in physical activity. As with many energy conserving or "thrifty" genes, this may explain their association with obesity and insulin resistance in multiple ethnic groups (Burguete-Garcia et al. 2014; Deschamps and Hittel 2016; Kim et al. 2010; Sakane et al. 2016; Takenaka et al. 2012; Wagoner et al. 2002; Widen et al. 1995).

Associations between physical activity behaviours and adrenergic receptor genotypes underscores the influence of genetics on behaviour (de Geus et al. 2014; Lee et al. 2015; Perusse et al. 1989; Stubbe et al. 2006). For instance, researchers from the Social Science Genetics Association Consortium (SSGAC) have recently identified a 
connection between the genetic components of cognition and years of formal education (Kovas and Malykh 2016). Therefore, given the unique focus on exercise and athletics encapsulated by the modern kinesiology student, it follows that individuals with an innately higher drive towards exercise would be drawn to such programs (Many et al. 2016).

Despite their primary roles in the sympathetic control of cardiac output and lipolysis, $\beta 1$ and $\beta 3$-adrenergic receptors are also localized to neuronal synapses in the basolateral amygdala where they modulate anxiolytic (anxiety reducing) and other behaviours (Stemmelin et al. 2008). Indeed, recent published research supports a role for the $A D R B 1$ Arg389Gly polymorphism in both the perception of pain (Wei et al. 2015) and the psychological trait of persistence as assessed by the temperament and character inventory (Numajiri et al. 2012). In addition, $\beta 3$-adrenergic receptor agonists such as SR58611A (amibegron) have proven to be an effective treatment strategy for anxiety and depressive disorders (Stemmelin et al. 2008). Because both ADRB1 Arg389Gly and ADRB3 Trp64Arg polymorphisms decrease agonist mediated coupling of activated receptors to adenylate cyclase activity (Fujisawa et al. 1996), it is conceivable that these polymorphisms may alter the perception and/or enjoyment of habitual exercise. Given the poorly understood role of the adrenergic system in the brain our findings provide a plausible experimental framework for testing the effect adrenergic receptor polymorphisms on the perception of exercise intensity and fatigue.

The effect of $\beta$-adrenergic receptor function on cardiovascular physiology has also been well studied (Kim et al. 2010; Snyder et al. 2006; Twentyman et al. 1981; Wagoner et al. 2002). As we observed in our AIMMY cohort, heart failure patients 
homozygous for the $A D R B 1389 \mathrm{Gly}$ polymorphism had significantly lower peak $\mathrm{VO}_{2}$ compared with those with one or more copy of the Arg389 receptor (Wagoner et al. 2002). Similarly, associations of the $A D R B 3$ Trp64Arg polymorphism with elite endurance performance in Spanish cyclists and Korean volleyball players suggests a role for this gene in regulating the cardiovascular response to exercise (Santiago et al. 2011). As such, it is also possible that the higher levels of physical activity associated with ancestral $A D R B 1$ and $A D R B 3$ genotypes may attributable to a more efficient cardiovascular and metabolic response to exercise. As such, increased cardiometabolic efficiency may influence perception of exercise difficulty and thus influence participation (Oliver 2012).

Freshman university students are an ideal population to target education about lifelong fitness habits that will shape future health (Many et al. 2016). This is particularly true for female carriers of $A D R B 3$ Trp64Arg polymorphism in our AIMMY cohort who exhibit elevated triglycerides and HOMA-IR at a relatively young age (Table 3B). Furthermore, $A D R B 3$ Trp64Arg has been designated as a risk allele based on research linking it to weight gain and an early risk for developing cardiovascular disease in women (Clement et al. 1995; Kumar et al. 2014). On the other hand, high fitness levels in carriers of the $A D R B 3$ Trp64Arg polymorphism have been shown to eliminate the increased risk of atherosclerosis associated with this common variant (Iemitsu et al. 2014). This is consistent with our observation that associations between ADRB3 and RPE and $A D R B 1$ with fatigue were only significant in non-majors compared to kinesiology students. This suggests that possession of one or more $A D R B$ risk loci is not deterministic in regards to cardiometabolic risk and lends strength to our argument that physical 
activity may be the mechanistic bridge between polymorphisms in the beta-adrenergic receptor and the development of obesity and insulin resistance. These findings may indicate that an accredited kinesiology curriculum, which includes courses in exercise physiology, motor learning and sports psychology can potentially overcome genotypeassociated limitations on physical activity.

Whereas once we held a dichotomous view of nature (genes) vs nurture (environment), a more nuanced model is emerging wherein gene-environment interactions affect our perceptions and choice of educational setting (Okbay et al. 2016). Although significant limitations of this study include the realtively small sample size and post-hoc nature of our analysis, it is of future interest to our laboratory to examine the genomic characteristics of a significantly larger cohort of kinesiology students (Nedovic et al. 2016). Apart from these findings, there are many fascinating research directions that may be explored involving the application of our research. For instance, individuals who are polymorphic for $A D R B 1$ and 3 risk alleles may need extra assistance (personal trainer or feedback from a wearable fitness monitor or app) to adhere to prescribed exercise program, not because they are lazy or unmotivated, rather that exercise is perceived as harder for them. In addition, exercise behavior and aptitude genes could be used in Mendelian randomization studies proxies for physical activity to better discern the effects of environmental and social factors on cardiometabolic health (Burgess and Harshfield 2016). Findings from this study are also of importance for identifying and removing barriers to physical activity given the strong association of sedentary behavior with all-cause morbidity (Deforche et al. 2015; Friedenreich et al. 2006). 


\section{Conflict of Interest Statement}

The authors report no conflicts on interest associated with this manuscript.

\section{Acknowledgements}

DSH and CLD were funded by philanthropic donations from the Eresman Family and BURNCO Foundations, Jay and Karen Westman. DSH and JS are individually funded by a Discovery Grant from the Natural Sciences and Engineering Research Counsel of Canada (NSERC). GMM was funded by a NIH postdoctoral training grant T32HD071866 as well as the Clark Charitable Foundation, Inc. This study is funded in part by the Children's National Medical Center General Clinical Research Center (5M01-RR-020359-02), the DC-Baltimore Research Center on Child Health Disparities (5P20MD00165), The Dairy Research Institute, NICHD/NINDS 5R24HD050846-08: NCMRR-DC Core Molecular and Functional Outcome Measures in Rehabilitation Medicine. The funders had no role in study design, data collection and analysis, decision to publish, or preparation of the manuscript. 


\section{References}

Auer, P.L., Johnsen, J.M., Johnson, A.D., Logsdon, B.A., Lange, L.A., Nalls, M.A. et al. 2012. Imputation of exome sequence variants into population- based samples and bloodcell-trait-associated loci in African Americans: NHLBI GO Exome Sequencing Project. Am. J. Hum. Genet. 91(5): 794-808. doi:10.1016/j.ajhg.2012.08.031

Bouchard, C., Hoffman, E.P., and Commission, I.M. 2011. Genetic and molecular aspects of sports performance: Wiley Online Library. doi: 10.1002/9781444327335

Bray, M.S., Loos, R.J., McCaffery, J.M., Ling, C., Franks, P.W., Weinstock, G.M et al. 2016. NIH working group report-using genomic information to guide weight management: From universal to precision treatment. Obesity (Silver Spring) 24(1): 1422. doi:10.1002/oby.21381

Burgess, S. and Harshfield, E. 2016. Mendelian randomization to assess causal effects of blood lipids on coronary heart disease: lessons from the past and applications to the future. Curr. Opin. Endocrinol. Diabetes. Obes. 23(2): 124-30.

doi:10.1097/MED.0000000000000230

Burguete-Garcia, A.I., Martinez-Nava, G.A., Valladares-Salgado, A., Bermudez Morales, V.H., Estrada-Velasco, B., Wacher, N. et al. 2014. Association of beta1 and beta3 adrenergic receptors gene polymorphisms with insulin resistance and high lipid profiles related to type 2 diabetes and metabolic syndrome. Nutr. Hosp. 29(6): 1327-34. doi:10.3305/nh.2014.29.6.7367

Chan, S., Seto, J.T., MacArthur, D.G., Yang, N., North, K.N., and Head, S.I. 2008. A gene for speed: contractile properties of isolated whole EDL muscle from an alpha- 
actinin-3 knockout mouse. Am. J. Physiol. Cell. Physiol. 295(4): C897-904. doi:10.1152/ajpcell.00179.2008

Chang, J.S., Fernand, V., Zhang, Y., Shin, J., Jun, H.J., Joshi, Y. et al. 2012. NT-PGC1alpha protein is sufficient to link beta3-adrenergic receptor activation to transcriptional and physiological components of adaptive thermogenesis. J. Biol. Chem. 287(12): 910011. doi:10.1074/jbc.M111.320200

Clarkson, P.M., Hoffman, E.P., Zambraski, E., Gordish-Dressman, H., Kearns, A., Hubal, M. et al. 2005. ACTN3 and MLCK genotype associations with exertional muscle damage. J. Appl. Physiol. (1985) 99(2): 564-9. doi:10.1152/japplphysiol.00130.2005 Clement, K., Vaisse, C., Manning, B.S., Basdevant, A., Guy-Grand, B., Ruiz, J. et al. 1995. Genetic variation in the beta 3 -adrenergic receptor and an increased capacity to gain weight in patients with morbid obesity. N. Engl. J. Med. 333(6): 352-4. doi:10.1056/NEJM199508103330605

Cowie, C.C., Rust, K.F., Byrd-Holt, D.D., Eberhardt, M.S., Flegal, K.M., Engelgau, M.M. et al. 2006. Prevalence of diabetes and impaired fasting glucose in adults in the U.S. population: National Health And Nutrition Examination Survey 1999-2002.

Diabetes Care 29(6): 1263-8. doi:10.2337/dc06-0062

de Geus, E.J., Bartels, M., Kaprio, J., Lightfoot, J.T., and Thomis, M. 2014. Genetics of regular exercise and sedentary behaviors. Twin. Res. Hum.Genet. 17(4): 262-71. doi: $10.1017 /$ thg. 2014.42

Deforche, B., Van Dyck, D., Deliens, T., and De Bourdeaudhuij, I. 2015. Changes in weight, physical activity, sedentary behaviour and dietary intake during the transition to 
higher education: a prospective study. Int. J. Behav. Nutr. Phys. Act. 12: 16. doi:10.1186/s12966-015-0173-9

Delmonico, M.J., Kostek, M.C., Doldo, N.A., Hand, B.D., Walsh, S., Conway, J.M. et al. 2007. Alpha-actinin-3 (ACTN3) R577X polymorphism influences knee extensor peak power response to strength training in older men and women. J. Gerontol. A. Biol. Sci. Med. Sci. 62(2): 206-12.

Deschamps, C.L., Connors, K.E., Klein, M.S., Johnsen, V.L., Shearer, J., Vogel, H.J. et al. 2015. The ACTN3 R577X Polymorphism Is Associated with Cardiometabolic Fitness in Healthy Young Adults. PLoS One 10(6): e0130644. doi:10.1371/journal.pone.0130644 Deschamps, C.L. and Hittel, D.S. 2016. Actn3: A Thrifty Gene for Speed? Endocr. Pract. 22(7): 897-8. doi:10.4158/EP161277.CO

Eynon, N., Banting, L.K., Ruiz, J.R., Cieszczyk, P., Dyatlov, D.A., MaciejewskaKarlowska, A. et al. 2014. ACTN3 R577X polymorphism and team-sport performance: a study involving three European cohorts. J. Sci. Med. Sport. 17(1): 102-6. doi:10.1016/j.jsams.2013.02.005

Fiuza-Luces, C., Garatachea, N., Berger, N.A., and Lucia, A. 2013. Exercise is the real polypill. Physiology (Bethesda) 28(5): 330-58. doi:10.1152/physiol.00019.2013 Friedenreich, C.M., Courneya, K.S., Neilson, H.K., Matthews, C.E., Willis, G., Irwin, M. et al. 2006. Reliability and validity of the past year total physical activity questionnaire. American Journal of Epidemiology 163(10): 959-970.

Fujisawa, T., Ikegami, H., Yamato, E., Takekawa, K., Nakagawa, Y., Hamada, Y. et al. 1996. Association of Trp64Arg mutation of the beta3-adrenergic-receptor with NIDDM and body weight gain. Diabetologia, 39(3): 349-52. 
Houmard, J.A., Tanner, C.J., Slentz, C.A., Duscha, B.D., McCartney, J.S., and Kraus, W.E. 2004. Effect of the volume and intensity of exercise training on insulin sensitivity. J. Appl. Physiol. (1985) 96(1): 101-6. doi:10.1152/japplphysiol.00707.2003

Iemitsu, M., Fujie, S., Murakami, H., Sanada, K., Kawano, H., Gando, Y. 2014. Higher cardiorespiratory fitness attenuates the risk of atherosclerosis associated with ADRB3 Trp64Arg polymorphism. Eur. J. Appl. Physiol. 114(7): 1421-8. doi:10.1007/s00421$014-2862-5$

Irving, B.A., Rutkowski, J., Brock, D.W., Davis, C.K., Barrett, E.J., Gaesser, G.A. et al. 2006. Comparison of Borg- and OMNI-RPE as markers of the blood lactate response to exercise. Med. Sci. Sports. Exerc. 38(7): 1348-52.

doi:10.1249/01.mss.0000227322.61964.d2

Johns, M.W. 1991. A new method for measuring daytime sleepiness: the Epworth sleepiness scale. Sleep, 14(6): 540-5.

Johnson, J.L., Slentz, C.A., Duscha, B.D., Samsa, G.P., McCartney, J.S., Houmard, J.A. et al. 2004. Gender and racial differences in lipoprotein subclass distributions: the STRRIDE study. Atherosclerosis, 176(2): 371-7.

doi:10.1016/j.atherosclerosis.2004.05.018

Karlos, A., Shearer, J., Gnatiuk, E., Onyewu, C., Many, G., Hoffman, E.P. et al. 2013. Effect of the SORT1 low-density lipoprotein cholesterol locus is sex-specific in a fit, Canadian young-adult population. Appl. Physiol. Nutr. Metab. 38(2): 188-93.

doi:10.1139/apnm-2012-0231

Katzmarzyk, P.T. and Janssen, I. 2004. The economic costs associated with physical inactivity and obesity in Canada: an update. Can. J. Appl. Physiol. 29(1): 90-115. 
Kim, S.M., Oh, S.D., Jung, I.G., Lee, J., Sim, Y.J., Lee, J.K. et al. 2010. Distribution of the Trp64Arg polymorphism in the beta3-adrenergic receptor gene in athletes and its influence on cardiovascular function. Kardiol. Pol. 68(8): 920-6.

Klein, M.S., Connors, K.E., Shearer, J., Vogel, H.J., and Hittel, D.S. 2014. Metabolomics reveals the sex specific effects of the SORT1 low-density lipoprotein cholesterol locus in healthy young adults. J. Proteome. Res. doi:10.1021/pr500659r

Kovas, Y. and Malykh, S. 2016. Conclusion: Behavioural Genomics and Education.In: Y. Kovas, S. Malykh, andD. Gaysina (Ed.)^(Eds.), Behavioural Genetics for Education, pp. 269-276. London: Palgrave Macmillan UK.

Kuehn, B.M. 2012. 1000 Genomes Project finds substantial genetic variation among populations. JAMA, 308(22): 2322, 2325. doi:10.1001/jama.2012.88674

Kumar, S., Mishra, A., Srivastava, A., Mittal, T., Garg, N., and Mittal, B. 2014.

Significant role of ADRB3 rs4994 towards the development of coronary artery disease.

Coron. Artery. Dis. 25(1): 29-34. doi:10.1097/MCA.0000000000000056

Lee, H., Ash, G.I., Angelopoulos, T.J., Gordon, P.M., Moyna, N.M., Visich, P.S. et al. 2015. Obesity-Related Genetic Variants and their Associations with Physical Activity. Sports. Med. Open. 1(1): 34. doi:10.1186/s40798-015-0036-6

MacArthur, D.G. and North, K.N. 2004. A gene for speed? The evolution and function of alpha-actinin-3. Bioessays, 26(7): 786-95. doi:10.1002/bies.20061

Many, G.M., Lutsch, A., Connors, K.E., Shearer, J., Brown, H.C., Ash, G. et al. 2016.

Examination of Lifestyle Behaviors and Cardiometabolic Risk Factors in University Students Enrolled in Kinesiology Degree Programs. J. Strength. Cond. Res. 30(4): 113746. doi:10.1519/JSC.0000000000000871 
Mills, M., Yang, N., Weinberger, R., Vander Woude, D.L., Beggs, A.H., Easteal, S. et al. 2001. Differential expression of the actin-binding proteins, alpha-actinin-2 and -3 , in different species: implications for the evolution of functional redundancy. Hum. Mol. Genet. 10(13): 1335-46. doi: 10.1093/hmg/10.13.1335

Myslicki, J.P., Shearer, J., Hittel, D.S., Hughey, C.C., and Belke, D.D. 2014. O-GlcNAc modification is associated with insulin sensitivity in the whole blood of healthy young adult males. Diabetol. Metab. Syndr. 6(1): 96. doi:10.1186/1758-5996-6-96 Nedovic, D., Panic, N., Pastorino, R., Ricciardi, W., and Boccia, S. 2016. Evaluation of the Endorsement of the STrengthening the REporting of Genetic Association Studies (STREGA) Statement on the Reporting Quality of Published Genetic Association Studies. J. Epidemiol. 26(8): 399-404. doi:10.2188/jea.JE20150173 Norman, B., Esbjornsson, M., Rundqvist, H., Osterlund, T., Glenmark, B., and Jansson, E. 2014. ACTN3 genotype and modulation of skeletal muscle response to exercise in human subjects. J. Appl. Physiol. (1985) 116(9): 1197-203.

doi:10.1152/japplphysiol.00557.2013

Numajiri, M., Aoki, J., Nishizawa, D., Kasai, S., Ogai, Y., Ikeda, K. et al. 2012. The association between beta-adrenergic receptor gene polymorphisms and personality traits. Nihon. Shinkei. Seishin.Yakurigaku. Zasshi. 32(4): 227-31.

Ogden, C.L., Carroll, M.D., Kit, B.K., andFlegal, K.M. 2014. Prevalence of childhood and adult obesity in the United States, 2011-2012. JAMA, 311(8): 806-14.

doi:10.1001/jama.2014.732 
Okbay, A., Beauchamp, J.P., Fontana, M.A., Lee, J.J., Pers, T.H., Rietveld, C.A. et al. 2016. Genome-wide association study identifies 74 loci associated with educational attainment. Nature, 533(7604): 539-42. doi:10.1038/nature17671

Oliver, A. 2012. A nudge too far? A nudge at all? On paying people to be healthy. Healthc. Pap. 12(4): 8-16.

Pedersen, B.K. and Saltin, B. 2015. Exercise as medicine - evidence for prescribing exercise as therapy in 26 different chronic diseases. Scan. J. Med. Sci. Spo. 25: 1-72. doi:10.1111/sms. 12581

Perusse, L., Tremblay, A., Leblanc, C., and Bouchard, C. 1989. Genetic and environmental influences on level of habitual physical activity and exercise participation. Am. J. Epidemiol. 129(5): 1012-22.

Rao, G., Powell-Wiley, T.M., Ancheta, I., Hairston, K., Kirley, K., Lear, S.A. et al. 2015. Identification of Obesity and Cardiovascular Risk in Ethnically and Racially Diverse Populations: A Scientific Statement From the American Heart Association. Circulation, 132(5): 457-72. doi:10.1161/CIR.0000000000000223

Sakane, N., Sato, J., Tsushita, K., Tsujii, S., Kotani, K. et al. 2016. Effects of lifestyle intervention on weight and metabolic parameters in patients with impaired glucose tolerance related to beta-3 adrenergic receptor gene polymorphism $\operatorname{Trp} 64 \operatorname{Arg}(\mathrm{C} / \mathrm{T})$ : Results from the Japan Diabetes Prevention Program. J. Diabetes. Investig. 7(3): 338-42. doi:10.1111/jdi.12426

Santiago, C., Ruiz, J.R., Buxens, A., Artieda, M., Arteta, D., Gonzalez-Freire, M. et al. 2011. Trp64Arg polymorphism in ADRB3 gene is associated with elite endurance performance. Br. J. Sports. Med. 45(2): 147-9. doi:10.1136/bjsm.2009.061366 
Shah, B.N. 2013. On the 50th anniversary of the first description of a multistage exercise treadmill test: re-visiting the birth of the 'Bruce protocol'. Heart, 99(24): 1793-4. doi:10.1136/heartjnl-2013-304003

Simpson, K., Parker, B., Capizzi, J., Thompson, P., Clarkson, P., Freedson, P. et al. 2015. Validity and reliability of the Paffenbarger Physical Activity Questionnaire among healthy adults. J. Phys. Act. Health. 12(1): 116-23. doi:10.1123/jpah.2013-0013 Snyder, E.M., Beck, K.C., Dietz, N.M., Eisenach, J.H., Joyner, M.J., Turner, S.T. et al. 2006. Arg16Gly polymorphism of the beta2-adrenergic receptor is associated with differences in cardiovascular function at rest and during exercise in humans. J. Physiol. 571(Pt 1): 121-30. doi:10.1113/jphysiol.2005.098558

Stemmelin, J., Cohen, C., Terranova, J.P., Lopez-Grancha, M., Pichat, P., Bergis, O. et al. 2008. Stimulation of the beta3-Adrenoceptor as a novel treatment strategy for anxiety and depressive disorders. Neuropsychopharmacology, 33(3): 574-87.

doi:10.1038/sj.npp.1301424

Stubbe, J.H., Boomsma, D.I., Vink, J.M., Cornes, B.K., Martin, N.G., Skytthe, A. et al. 2006. Genetic influences on exercise participation in 37,051 twin pairs from seven countries. PLoS One 1: e22. doi:10.1371/journal.pone.0000022 Takenaka, A., Nakamura, S., Mitsunaga, F., Inoue-Murayama, M., Udono, T., and Suryobroto, B. 2012. Human-specific SNP in obesity genes, adrenergic receptor beta2 (ADRB2), Beta3 (ADRB3), and PPAR gamma2 (PPARG), during primate evolution. PLoS One 7(8): e43461. doi:10.1371/journal.pone.0043461 
Twentyman, O.P., Disley, A., Gribbin, H.R., Alberti, K.G., and Tattersfield, A.E. 1981. Effect of beta-adrenergic blockade on respiratory and metabolic responses to exercise. J. Appl. Physiol. Respir. Environ. Exerc. Physiol. 51(4): 788-93.

Ueta, C.B., Fernandes, G.W., Capelo, L.P., Fonseca, T.L., Maculan, F.D., Gouveia, C.H. et al. 2012. beta(1) Adrenergic receptor is key to cold- and diet-induced thermogenesis in mice. J. Endocrinol. 214(3): 359-65. doi:10.1530/JOE-12-0155

Wagoner, L.E., Craft, L.L., Zengel, P., McGuire, N., Rathz, D.A., Dorn, G.W. et al. 2002. Polymorphisms of the beta1-adrenergic receptor predict exercise capacity in heart failure. Am. Heart. J. 144(5): 840-6. doi:10.1067/mhj.2002.125325

Walston, J., Silver, K., Bogardus, C., Knowler, W.C., Celi, F.S., Austin, S. et al. 1995. Time of onset of non-insulin-dependent diabetes mellitus and genetic variation in the beta 3-adrenergic-receptor gene. N. Engl. J. Med. 333(6): 343-7.

doi:10.1056/NEJM199508103330603

Wei, W., Tian, Y., Zhao, C., Sui, Z., Liu, C., Wang, C. et al. 2015. Correlation of ADRB1 rs1801253 Polymorphism with Analgesic Effect of Fentanyl After Cancer Surgeries. Med. Sci. Moni.t 21: 4000-5.

Widen, E., Lehto, M., Kanninen, T., Walston, J., Shuldiner, A.R., and Groop, L.C. 1995. Association of a polymorphism in the beta 3-adrenergic-receptor gene with features of the insulin resistance syndrome in Finns. N. Engl. J. Med. 333(6): 348-51. doi:10.1056/NEJM199508103330604 
Table 1. ANCOVA comparisons of original AIMMY cohort characteristics between kinesiology (KNES) and non-kinesiology majors (NON). Data are mean values +/- SEM. Significant $P$ values $\leq 0.05$ are shaded and NS indicates non-significant differences.

\begin{tabular}{|l|c|c|c|}
\hline \multicolumn{1}{|c|}{ Subject Characteristics } & $\begin{array}{c}\text { KNES Majors } \\
\mathbf{n = 9 9}\end{array}$ & $\begin{array}{c}\text { Non-Majors } \\
\mathbf{n = 1 8 9}\end{array}$ & $\boldsymbol{P}$-Value \\
\hline Age (y) & $22.09 \pm 0.34$ & $22.24 \pm 0.33$ & $\mathrm{NS}$ \\
\hline Height $(\mathrm{cm})$ & $171.93 \pm 0.95$ & $172.31 \pm 0.76$ & $\mathrm{NS}$ \\
\hline Weight $(\mathrm{kg})$ & $70.85 \pm 0.95$ & $72.45 \pm 0.76$ & $\mathrm{NS}$ \\
\hline BMI & $23.31 \pm 0.29$ & $23.71 \pm 0.31$ & $\mathrm{NS}$ \\
\hline \% Body Fat & $19.20 \pm 0.94$ & $23.83 \pm 0.92$ & 0.002 \\
\hline Hip (cm) & $98.00 \pm 0.74$ & $99.40 \pm 0.77$ & $\mathrm{NS}$ \\
\hline Triglycerides (mg/dL) & $80.31 \pm 4.03$ & $85.51 \pm 2.98$ & $\mathrm{NS}$ \\
\hline Cholesterol (mg/dL) & $158.61 \pm 3.41$ & $162.18 \pm 2.45$ & $\mathrm{NS}$ \\
\hline HDL (mg/dL) & $62.07 \pm 2.13$ & $60.37 \pm 1.23$ & $\mathrm{NS}$ \\
\hline LDL (mg/dL) & $83.41 \pm 2.96$ & $84.63 \pm 1.75$ & $\mathrm{NS}$ \\
\hline Glucose (mg/dL) & $80.56 \pm 0.68$ & $83.37 \pm 0.47$ & $\mathrm{NS}$ \\
\hline Insulin (uIU/ml) & $5.34 \pm 0.30$ & $6.56 \pm 0.28$ & 0.007 \\
\hline \% HbA1c & $5.48 \pm 0.03$ & $5.48 \pm 0.02$ & $\mathrm{NS}$ \\
\hline HOMA-IR & $1.08 \pm 0.07$ & $1.32 \pm 0.07$ & 0.013 \\
\hline CRP (mg/L) & $1.19 \pm 0.24$ & $2.16 \pm 0.58$ & $\mathrm{NS}$ \\
\hline Grip Strength (kg) & $45.11 \pm 1.31$ & $42.51 \pm 1.15$ & $\mathrm{NS}$ \\
\hline BP-Systolic & $114.04 \pm 0.24$ & $112.56 \pm 0.24$ & $\mathrm{NS}$ \\
\hline BP-Diastolic & $67.67 \pm 0.24$ & $68.98 \pm 0.24$ & $\mathrm{NS}$ \\
\hline VO (ml/kg/min) & $48.26 \pm 0.24$ & $46.21 \pm 0.24$ & 0.026 \\
\hline
\end{tabular}

All models were adjusted for recruitment location, age and sex using a one-way analysis of covariance (ANCOVA). The Sidak method was used post-hoc to account for multiple comparisons. $\mathrm{BMI}=$ body mass index; $\mathrm{HDL}=$ high-density lipoprotein cholesterol; $\mathrm{LDL}=$ lowdensity lipoprotein cholesterol; HOMA-IR = homeostatic model assessment for insulin resistance. 
Table 2. ANCOVA comparisons of original AIMMY cohort physical activity survey data between kinesiology (KNES) and non-kinesiology majors (NON). Data are mean values $+/$ - SEM. Significant $P$ values $\leq 0.05$ are shaded and NS indicates non-significant differences.

\begin{tabular}{|l|c|c|c|}
\hline $\begin{array}{c}\text { Selected Physical Activity } \\
\text { Participation and Perception Scores }\end{array}$ & $\begin{array}{c}\text { KNES-Majors } \\
\mathrm{n}=99\end{array}$ & $\begin{array}{c}\text { NON-Majors } \\
\mathrm{n}=189\end{array}$ & $P$-Value \\
\hline Walking (kcal/week) & $1067.46 \pm 116.21$ & $844.07 \pm 54.49$ & $\mathrm{NS}$ \\
\hline Stair Climbing (kcal/week) & $398.91 \pm 62.81$ & $299.52 \pm 24.99$ & $\mathrm{NS}$ \\
\hline Combined (kcal/week) & $1466.37 \pm 145.06$ & $1143.59 \pm 63.84$ & $\mathrm{NS}$ \\
\hline Light Sports (kcal/week) & $391.06 \pm 59.98$ & $370.01 \pm 78.97$ & $\mathrm{NS}$ \\
\hline Moderate Sports (kcal/week) & $4043.86 \pm 483$ & $2873.77 \pm 287$ & 0.029 \\
\hline Vigorous Sports (kcal/week) & $5070.25 \pm 865$ & $2582.02 \pm 242$ & 0.0004 \\
\hline Total Sports (kcal/week) & $9505.17 \pm 1192$ & $5854.85 \pm 442$ & 0.0004 \\
\hline Total Physical Activity (kcal/week) & $10971.54 \pm 1271$ & $6998.44 \pm 454$ & 0.0005 \\
\hline Sitting Time (hours/week) & $42.03 \pm 1.99$ & $44.76 \pm 1.34$ & $\mathrm{NS}$ \\
\hline Borg CR-10 RPE (0-10) & $6.90 \pm 0.16$ & $6.30 \pm 0.13$ & 0.004 \\
\hline Epworth Afternoon Fatigue (1-3) & $1.96 \pm 0.10$ & $1.99 \pm 0.07$ & $\mathrm{NS}$ \\
\hline
\end{tabular}

All models were adjusted for recruitment location, age and sex using a one-way analysis of covariance (ANCOVA). The Sidak method was used post-hoc to account for multiple comparisons. $\mathrm{RPE}=$ Rate perceived exertion. 
Table 3. Significant associations of $A D R B 1$ and $A D R B 3$ genotypes with subject characteristics and physical activity patterns in our original (A) verification (B) and combined AIMMY cohorts. Shown are numbers for each genotype $(\mathrm{N})$, adjusted mean values $+/$ - SEM, and genotype $P$ values.

A.

\begin{tabular}{|cc|c|c|l|}
\hline SNP & Cohort & Phenotype & P-Value & N; Adjusted Mean \pm SEM \\
\hline $\begin{array}{c}\text { ADRB1 } \\
(\mathrm{rs} 1801253)\end{array}$ & $\begin{array}{c}\text { AIMMY } \\
(\mathrm{n}=288)\end{array}$ & $\begin{array}{c}\text { Moderate } \\
\text { Sports }\end{array}$ & 0.040 & $\begin{array}{l}\text { CC }(158 ; 3314.2 \pm 42.4) \\
\text { CG/GG }(130 ; 2141.3 \pm 69.7)\end{array}$ \\
$\begin{array}{c}\text { ADRB3 } \\
(\mathrm{rs} 4994)\end{array}$ & $\begin{array}{c}\text { AIMMY } \\
(\mathrm{n}=288)\end{array}$ & Borg CR10 & 0.008 & $\begin{array}{l}\text { AA }(255 ; 6.6 \pm 0.1) \\
\text { AG/GG }(33 ; 5.8 \pm 0.3)\end{array}$ \\
\hline $\begin{array}{c}\text { ADRB1 } \\
(\mathrm{rs} 1801253)\end{array}$ & $\begin{array}{c}\text { AIMMY } \\
(\mathrm{n}=288)\end{array}$ & $\begin{array}{c}\text { Epworth } \\
\text { Fatigue }\end{array}$ & 0.050 & $\begin{array}{l}\mathrm{CC}(158 ; 1.9 \pm 0.1) \\
\text { CG/GG }(130 ; 2.2 \pm 0.1)\end{array}$ \\
\hline
\end{tabular}

B.

\begin{tabular}{|cc|c|c|l|}
\hline SNP & Cohort & Phenotype & P-Value & N; Adjusted Mean \pm SEM \\
\hline $\begin{array}{c}\text { ADRB1 } \\
\text { (rs1801253) }\end{array}$ & $\begin{array}{c}\text { AIMMY } \\
(\mathrm{n}=207)\end{array}$ & $\begin{array}{c}\text { Moderate } \\
\text { Sports }\end{array}$ & 0.020 & $\begin{array}{l}\text { CC }(79 ; 3910.9 \pm 22.3) \\
\text { CG/GG }(128 ; 3161.6 \pm 39.1)\end{array}$ \\
\hline $\begin{array}{c}\text { ADRB3 } \\
\text { (rs4994) }\end{array}$ & $\begin{array}{c}\text { AIMMY } \\
(\mathrm{n}=207)\end{array}$ & Borg CR10 & 0.070 & $\begin{array}{l}\text { AA }(158 ; 6.3 \pm 0.1) \\
\text { AG/GG }(49 ; 5.8 \pm 0.1)\end{array}$ \\
\hline $\begin{array}{c}\text { ADRB1 } \\
\text { (rs1801253) }\end{array}$ & $\begin{array}{c}\text { AIMMY } \\
(\mathrm{n}=207)\end{array}$ & $\begin{array}{c}\text { Epworth } \\
\text { Fatigue }\end{array}$ & 0.060 & $\begin{array}{l}\text { CC }(79 ; 1.8 \pm 0.1) \\
\text { CG/GG }(128 ; 2.0 \pm 0.1)\end{array}$ \\
\hline
\end{tabular}

C.

\begin{tabular}{|cc|c|c|l|}
\hline SNP & Cohort & Phenotype & $\boldsymbol{P}$-Value & N; Adjusted Mean \pm SEM \\
\hline $\begin{array}{c}\text { ADRB1 } \\
(\mathrm{rs} 1801253)\end{array}$ & $\begin{array}{c}\text { AIMMY } \\
(\mathrm{n}=495)\end{array}$ & $\begin{array}{c}\text { Moderate } \\
\text { Sports }\end{array}$ & 0.030 & $\begin{array}{l}\mathrm{CC}(237 ; 3512.8 \pm 49.7) \\
\mathrm{CG} / \mathrm{GG}(258 ; 2736.8 \pm 42.4)\end{array}$ \\
\hline $\begin{array}{c}\text { ADRB3 } \\
(\mathrm{rs} 4994)\end{array}$ & $\begin{array}{c}\text { Females } \\
(\mathrm{n}=229)\end{array}$ & Borg CR10 & 0.050 & $\begin{array}{l}\mathrm{AA}(188 ; 6.4 \pm 0.1) \\
\mathrm{AG} / \mathrm{GG}(41 ; 5.8 \pm 0.1)\end{array}$ \\
\hline $\begin{array}{c}\text { ADRB1 } \\
(\mathrm{r} 1801253)\end{array}$ & $\begin{array}{c}\text { AIMMY } \\
(\mathrm{n}=495)\end{array}$ & $\begin{array}{c}\text { Epworth } \\
\text { Fatigue }\end{array}$ & 0.057 & $\begin{array}{l}\mathrm{CC}(237 ; 1.9 \pm 0.1) \\
\mathrm{CG} / \mathrm{GG}(258 ; 2.1 \pm 0.1)\end{array}$ \\
\hline $\begin{array}{c}\text { ADRB1 } \\
(\mathrm{r} 1801253)\end{array}$ & $\begin{array}{c}\text { AIMMY } \\
(\mathrm{n}=495)\end{array}$ & $\mathrm{VO}_{2}$ max & 0.040 & $\begin{array}{l}\mathrm{CC}(237 ; 43.1 \pm 0.9) \\
\mathrm{CG} / \mathrm{GG}(258 ; 39.8 \pm 1.3)\end{array}$ \\
\hline $\begin{array}{c}\text { ADRB3 } \\
(\mathrm{rs} 4994)\end{array}$ & $\begin{array}{c}\text { Females } \\
(\mathrm{n}=229)\end{array}$ & Triglycerides & 0.011 & $\begin{array}{l}\mathrm{AA}(188 ; 85.2 \pm 2.9) \\
\text { AG/GG }(41 ; 101.5 \pm 8.9)\end{array}$ \\
\hline $\begin{array}{c}\text { ADRB3 } \\
(\mathrm{rs} 4994)\end{array}$ & $\begin{array}{c}\text { Females } \\
(\mathrm{n}=229)\end{array}$ & HOMA-IR & 0.047 & $\begin{array}{l}\mathrm{AA}(188 ; 1.2 \pm 0.1) \\
\text { AG/GG }(41 ; 1.5 \pm 0.2)\end{array}$ \\
\hline
\end{tabular}

We used a dominant genetic model for genotype association with age and sex as possible covariates with the exception of B, where sexes were compared. All comparisons were made with 1-way analysis of covariance (ANCOVA) with the Sidak method for post-hoc multiple comparisons adjustment. 
Figure 1. Genotype distributions of ACTN3, ADRB1 and ADRB 3 gene variants in kinesiology majors (KNES) and non-majors (NON) from our AIMMY cohort of healthy young college students. 


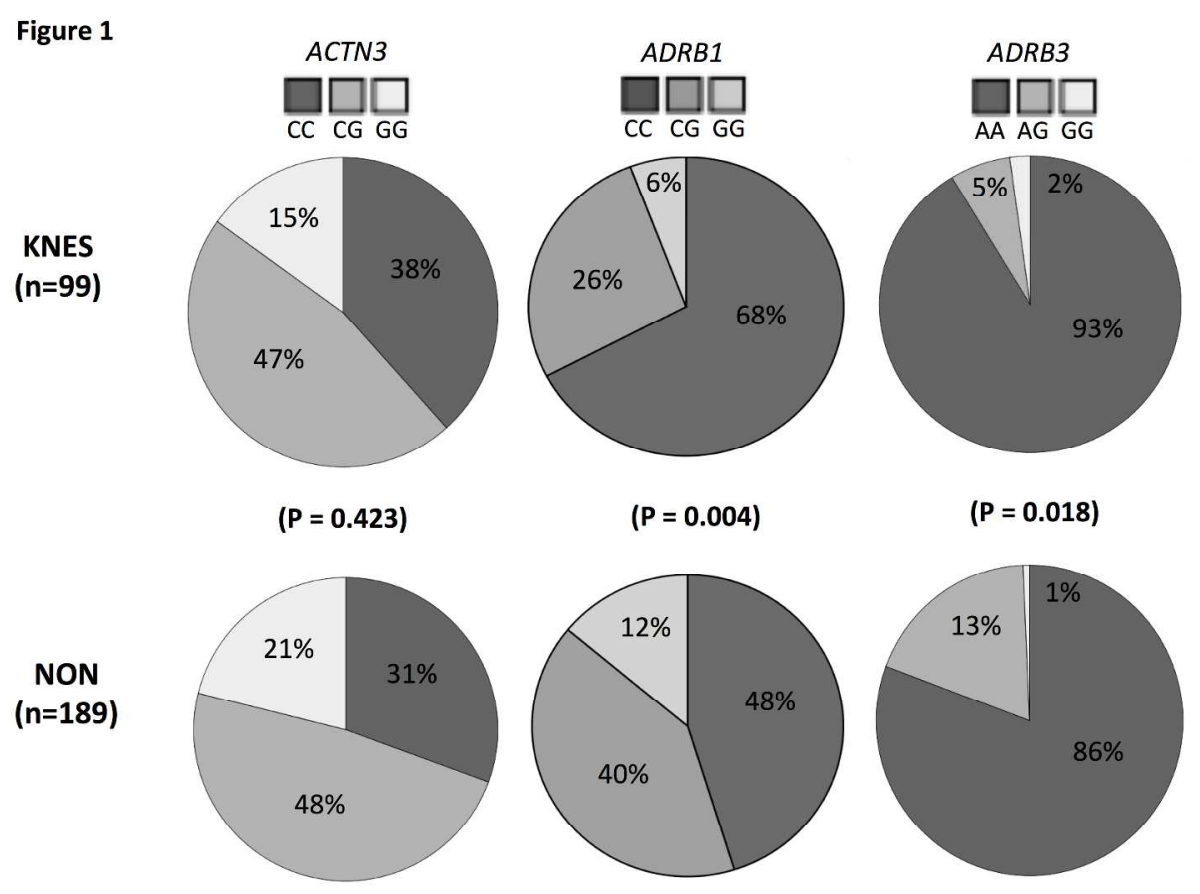

Figure 1. Genotype distributions of ACTN3, ADRB1 and ADRB 3 gene variants in kinesiology majors (KNES) and non-majors (NON) from our AIMMY cohort of healthy young college students.

Figure 1

$279 \times 215 \mathrm{~mm}(300 \times 300 \mathrm{DPI})$ 